(though we have also looked at other time intervals). This decision will also depend, to some extent, on the subject under study. For example, in monitoring the success of hip arthroplasties a much longer time period for readmission would be appropriate than in monitoring readmissions for infection after abdominal operations.

(9) If a patient is readmitted more than once after an index event a decision is needed on whether to count only the first readmission (as we did) or to count each subsequent readmission. Similarly, a decision is needed on whether a readmission should be counted as both a readmission and a new index event from which further readmissions might occur.

(10) Decisions are needed on whether and how to define different sources of admission for the index event and for readmissions. We grouped sources of admission for index events and readmissions as immediate or elective admissions. The recording of immediate and elective admissions may not be wholly uniform. Anecdote suggests that clinicians who wish to circumvent long waits for elective admissions may, on occasion, deem the patient to require emergency admission.

1 Goldacre MJ, Simmons H, Henderson J, Gill LE. Trends in episode based and person based rates of admission to hospital in the Oxford record linkage study area. Br Med f 1988;296:583-5.

2 Anderson GF, Steinberg EP. Predicting hospital readmissions in the Medicare population. Inquiry 1985;22:251-8
3 Roos LL, Cageorge SM, Roos NP, Danzinger R. Centralization, certification and monitoring: readmissions and complications after surgery. Med Care 1986;24: 1044-66

4 Victor CR, Vetter NJ. The early readmission of the elderly to hospital. Age Ageing 1985;14:37-42.

5 Odetunde ZO. Early readmission of the elderly into hospital. Physiotherapy 1987;73:631-4

6 Williams EI, Fitton F. Factors affecting early unplanned readmission of elderly patients to hospital. Br Med f 1988;297:784-7.

Klein R. Performance, evaluation and the NHS: a case study in conceptual perplexity and organisational complexity. Public Administration 1982;60: $385-407$

8 Downey G. How efficient is the NHS? Hospital and Health Services Review 1988;79:117-21.

9 Health Service Indicators Group. A report on Körner indicators. London: Department of Health, 1988:9.

10 Steering Group on Health Services Information (chairman: Mrs E Körner). First report to the secretary of state. London: HMSO, 1982.

11 Acheson ED. Medical record linkage. London: Oxford University Press, 1967. Acheson ED, Barr A. Multiple spells of in-patient treatment in a calendar year British fournal of Preventive and Social Medicine 1965;19:182-91.

13 Armitage P, Berry G. Statistical methods in medical research. 2nd ed. Oxford Blackwell Scientific, 1987;399-403.

14 Department of Health and Social Security. Performance indicators in the NHS London: DHSS, 1982. (RA(82)34.)

15 Secretaries of State for Health, Wales, Northern Ireland, and Scotland. Working for patients. London: HMSO, 1989. (Cmnd 555.)

16 Henderson J, Goldacre MJ, Griffith M, Simmons HM. Day case surgery: geographical variation, trends and readmission rates. $\mathcal{f}$ Epidemiol Com munity Health (in press).
Institute of Psychiatry, London SE5 8AF

Michael B King, MRCGP, senior lecturer

Correspondence to:

Academic Department of

Psychiatry, Royal Free

Hospital, London

NE3 2QG.

$\operatorname{BrMed} \mathcal{F} 1989 ; 299: 713-7$

\title{
Psychological and social problems in HIV infection: interviews with general practitioners in London
}

\author{
Michael B King
}

\section{Abstract}

Objective-To assess current practice and opinions of general practitioners in London about managing psychological and social problems relating to HIV infection.

Design-A stratified random sample of general practitioners, including those with a range of experience of people with HIV infection, were interviewed by medically trained interviewers.

Setting-Doctors' surgeries.

Participants -270 General practitioners working within the area covered by London postcodes.

Results - Two thirds of doctors had treated at least one patient with HIV infection and described their work with these patients. General practitioners were counselling and educating many of their patients about AIDS and associated risk behaviours and were aware of the need for careful attention to confidentiality. Doctors with no experience of patients with HIV infection were often older, in singlehanded practice, less inclined to deal with drug abusers or to counsel their patients on risk behaviours, and more in favour of insurance companies' policies towards people with HIV infection.

Conclusions-General practitioners in London are quickly becoming involved in the care of patients with HIV infection and their relatives and friends. Many are counselling patients and testing for antibodies themselves and regard this as an integral part of their work. A considerable workload in primary care comprised patients who obsessively fear contracting HIV infection.

\section{Introduction}

"Familial and social rejection of homosexuals leaves many AIDS patients alone with their disease-and their physicians." With the growing prevalence of AIDS and the emphasis on providing care in the community the relationship between general practi- tioners and patients with HIV infection has become a focus of increasing interest. ${ }^{23}$ Although patients would prefer family doctors to take part in their care, they are reluctant to consult them out of fear of rejection or lack of confidentiality or because they do not consider their doctor knowledgeable about AIDS. ${ }^{+5}$ There have now been eight published surveys of the attitudes of general practitioners in Britain towards HIV infection, ${ }^{6-13}$ some of which entailed small numbers and all of which used postal questionnaires to deal with mainly public health issues. Only four included doctors in London, the city in Britain with the greatest concentration of people infected with HIV. Postal questionnaires are useful for an overview of attitudes but by relying on predominantly forced choice responses ultimately fail to deal with the complexitv of issues related to AIDS. ${ }^{9}$ If family doctors are to play a central part in the community care of patients with HIV infection ${ }^{1415}$ it is essential to identify and report their needs in preparing to meet this challenge. ${ }^{15}$

By interviewing a sample of London general practitioners in depth I aimed at assessing their current participation in the psychological and social problems of patients with HIV infection. These interviews took place three months after a postal survey in which all general practitioners in London were sent a questionnaire on numbers of patients with HIV infection under their care and their attitudes towards and knowledge of the psychological, social, and ethical problems of HIV infection. ${ }^{12}$

\section{Subjects and methods}

General practitioners working within the areas covered by London postcodes were selected for interview to obtain a group of doctors with a range of experience of HIV from those with no patients with HIV infection to those with considerable numbers. Doctors were chosen from the list of a commercial mailing company that regularly updated names and 
addresses. Thus two groups were chosen: firstly, a random sample of 140 doctors, about half of whom had replied to the original postal questionnaire; and, secondly, a further random sample of 185 doctors, all of whom had replied to the postal questionnaire, stratified according to the numbers of patients with HIV infection they had reported in the postal survey. The random sample was chosen to make the population as representative of general practitioners in London as possible by including doctors who had not answered the original postal questionnaire.

A semistructured interview designed to explore management of psychosocial problems in patients with $\mathrm{HIV}$ infection was piloted with 14 general practitioners before final modification. Medically qualified interviewers approached each doctor after a letter had been sent introducing the study. After initial training seminars were held with interviewers to monitor their use of the interview. When a general practitioner had moved or retired his or her replacement was asked for an interview. No replacement was sought when a doctor refused an interview. Interviews took place during April to October 1988.

\section{Results}

One hundred and ten doctors (79\%) in the first group and $160(86 \%)$ in the second agreed to be interviewed, so that 270 doctors $(83 \%)$ were interviewed overall. One hundred and forty three doctors practised in west London (postcodes SW, NW, W, WC) and 130 in east London (codes SE, N, E, EC). Table I shows other demographic factors. Besides their general practice work 44 doctors did NHS hospital sessions and 62 had research interests.

One hundred and fifty four doctors reported at least one consultation in the preceding month with a patient worried about contracting HIV, and 11 of these reported 10 or more such attenders in the month. Only 44 general practitioners had never recommended a test for HIV antibody, though they might have discussed HIV infection with a patient. Eighty nine had performed at least one test themselves without referral to hospital.

Two hundred and forty eight doctors were able to describe their most recent consultation in which a test for HIV had been discussed. (The remainder had never considered the possibility of HIV infection with a patient.) Of these, 217 had given their patients some form of counselling, usually assessing the need for a test by exploring their lifestyle and giving information on the test and its implications for insurance purposes. Those who had not counselled their patients seemed to assume that this would be done by clinics for sexually transmitted diseases or other organisations.

Only 67 said they had counselled their patients after the result of the test was known, chiefly discussing the consequences for the patient's sex life and partners and providing information on the test and on AIDS. Of these, 25 provided specific support for the emotional impact of the test. Seventy six had considered further counselling unnecessary as the result was negative, while in the remainder the patient had not been tested or had not returned to the surgery. Only 21 doctors felt uncertain about giving this counselling and education.

PRACTICE BY DOCTORS CARING FOR PATIENTS WITH HIV INFECTION

One hundred and seventy three doctors reported caring for at least one patient with HIV infection or AIDS, 35 of whom had more than 10 patients. The mean number of patients with HIV infection was $5 \cdot 7$ (range 1 to 54 ) and of those with AIDS 2.4 (1 to 20).

Patients with psychological problems-Although 58 general practitioners had not encountered any psycho- logical problems in their patients with HIV infection the remainder cited anxiety, depression, and fear of exposure as the commonest (table II). Sixty nine ( $40 \%$ of those with patients with HIV infection) had referred patients to outside agencies for help with emotional problems, usually charitable counselling organisations in London such as the Terrence Higgins Trust and Body Positive. Referrals to a psychiatrist or psychologist had been made by 21 doctors.

Consultation with sexual partners, family, and friends -Fifty eight doctors (34\% of those with patients with HIV infection) had been consulted by their patients' sexual partners. They were mainly advised about AIDS, their relationship with the patient, their chances of being HIV positive, and the need for a test for HIV antibody. Although some partners expressed concern about caring for the patient, this was much less common. Eight general practitioners on their own initiative had attempted to help partners of patients with HIV infection. Forty nine doctors (28\% of those with patients with HIV infection) had been consulted by members of patients' families, mainly for advice on medical aspects of AIDS and the risk posed to themselves, and nine had helped bereaved relatives. Although only 25 doctors had been consulted by close friends of patients, more than half of these friends were concerned about contracting HIV infection.

Reports to employers or other third parties-Medical reports given by doctors often raise problems of confidentiality. Twenty three doctors had been asked by employers for medical reports on their patients with HIV infection, and though 19 had supplied the reports, only 10 had mentioned HIV infection. Altogether, 58 ( $34 \%$ of those with patients with HIV infection) had withheld information about HIV from third parties, of whom 41 cited insurance companies as the main group.

Management of deaths of patients with AIDS - When asked about the terminal care of their patients with AIDS 32 doctors (18\% of those with patients with HIV infection) said that they had managed a patient dying at home, and six were doing so at the time of interview. Agencies supporting the practitioner were district nurses (16), AIDS domiciliary teams (11), other doctors (nine), voluntary organisations (eight), and social workers (six). Only two doctors had carried out this work with no help from other agencies. Although 14 reported that the experience was difficult, most considered it worth while and satisfying, and only two had experienced such severe difficulties that they would not attempt domiciliary care in the future.

Contact with hospital clinics for HIV infectionHospital clinics dealing with HIV infection were often in contact with these primary care doctors. Help or advice from clinics had been received by 111 doctors (64\% of those with patients with HIV infection). Although it was quite common for hospital departments to inform the general practitioner when a patient was first found to be positive for HIV, 31 doctors also claimed to have been informed about patients by clinics for sexually transmitted diseases.

Testing for HIV antibody without consent-Ten doctors had performed tests for HIV without the knowledge or consent of their patient, seven claiming that they did not want to frighten or insult them. Only one admitted that the test had been done for her or his own protection. In three instances the result of the test was positive. The first was a baby who had received a blood transfusion and whose mother became very depressed and angry on hearing the result. The second was a man who continued to deny any at risk behaviour but took the result calmly. In the third instance, the doctor (who had carried out this policy on several occasions) did not inform the patient. Instead, if symptoms appeared he intended to suggest a test and carry it out again. 
Influence of patients with HIV infection on the practice - Only one doctor admitted to having removed a patient with HIV infection from his list, the patient being "uncooperative" and "reluctant to accept treatment." Thirty four practitioners $(20 \%$ of those with patients with HIV infection) tagged the notes of their patients with HIV infection in some way, usually with a warning flag or a notice inside the envelope containing the notes, and only three used a discreet code for this procedure. A few doctors (13) had experienced reactions from other patients who were upset that people with HIV were treated in the practice. Many doctors, however, believed that most of their patients were unaware that they saw patients with HIV.

OPINIONS AND PRACTICE OF ALL DOCTORS INTERVIEWED

Attenders worried about possible HIV infection-Fifty five doctors reported consultations with patients who were concerned about a sexual partner who had been shown positive for HIV antibody or had developed AIDS. Doctors had usually given counselling and education on the test. Nevertheless, in 20 cases the doctor had arranged a test for HIV antibody and in a further 11 cases had referred the partner to a clinic for sexually transmitted diseases. One hundred and forty four general practitioners reported patients who were constantly fearful of developing AIDS and each described their most recent consultation. Three quarters of the patients were men and only three were known to be positive for HIV antibody. Although actions taken by doctors included counselling, reassurance, and education, 47 had resorted to a test for HIV antibody and 20 had referred the patient to the psychological services.

Use of other services-Although clinics for sexually transmitted diseases were originally established as a confidential, primary care resource, 132 doctors interviewed said that they would prefer to be informed about all their patients seen at the clinics (table III) regardless of whether they had referred them. Referral of patients to organisations apart from these clinics had been carried out by 100 practitioners, in most cases (77) to the Terrence Higgins Trust. Doctors were, however, familiar with other organisations, including 10 further counselling, education, and support bodies. In fact, 67 doctors claimed that they had had direct contact with at least one outside organisation regarding their patients, principally the Terrence Higgins Trust. Moreover, 115 doctors were aware of local psychiatric, psychological, or counselling services that took an interest in problems related to HIV.

TABI.F III - Information that doctors wanted from clinics for sexually transmitted diseases

\begin{tabular}{lc}
\hline Information required & $\begin{array}{c}\text { No of } \\
\text { doctors }\end{array}$ \\
\hline On all patients regardless of result of HIV test & 132 \\
On all patients who have a positive result & 47 \\
On all patients referred by general practitioner & 39 \\
None & 39 \\
It should be the patient's decision & 9 \\
Only on referred patients who have a positive result & 4
\end{tabular}

Terminal care-As general practitioners will often take part in the terminal care of patients with AIDS they were asked to discuss the various alternatives that they considered appropriate. Management at home was the preferred option with hospice care a close second. Seventy doctors emphasised that they would respect the patient's choice in the matter.

Sex education specific to prevention of HIV infectionTwo hundred and seventeen practitioners had given advice on "safer sex" to their heterosexual patients, 141 had done so to homosexual patients, and $83(48 \%$ of those with patients with HIV infection) had done so to their patients with HIV infection. Their main recommendations to heterosexuals were to restrict the number of partners and use condoms with all casual partners. Similar guidance was given to homosexuals with the added advice against penetrative sex, particularly anal but also oral. Many doctors, however, commented that their homosexual patients were familiar with these precautions and rarely consulted about them. The only difference for patients with HIV infection was a greater emphasis on the use of condoms. In fact, 191 doctors were prepared to have condoms freely available in their surgeries. Only 26 doctors advised patients with HIV infection to abstain completely from all sexual contacts.

Interest in AIDS-Although 49 doctors declared an interest in AIDS, most regarded it as part of their day to day routine. Only 36 disliked the work or considered themselves lacking in skill. Over half (145) had attended study days or seminars on AIDS, and 131 had found them worth while or helpful.

Patients rejected by other doctors-Although only one practitioner who treated patients with HIV had ever removed a patient from his list (see above), this was so obviously a sensitive question that the issue was approached from another angle. All doctors were asked if they had ever knowingly taken on patients removed from the lists of other practitioners. Many stated that they were not always sure when this was the case and were often sceptical of the patient's account. Nevertheless, 60 doctors were aware of intravenous drug abusers on their lists who claimed to have been rejected or refused registration by previous general practitioners, and 31 described patients with HIV infection or AIDS who had had similar reactions from previous doctors.

Views on insurance companies-One hundred and thirty seven practitioners were broadly in favour of the current policies of insurance companies, 117 were against, and 16 were undecided. When discussing what type of information insurance companies had a right to expect from the family doctor on prospective clients their views were mixed. A hundred doctors believed that companies had no right to any information and 79 considered that companies had a right to information on both sexual orientation and use of drugs. Many believed that contracts between companies and patients should not concern the doctor, and 69 claimed that they had withheld information on their patients' sexual orientation and 34 had withheld information on use of drugs. Several practices had written policies of refusing to comment in reports on the lifestyle of any patient. In addition, almost two thirds of general practitioners (171) said that they showed patients the contents of medical reports before sending them to insurance companies, and 146 also advised patients against taking a test for HIV antibody because of the implications for insurance.

Confidentiality of patients' records-One hundred and thirteen doctors judged their own records more secure and confidential than those of clinics for sexually transmitted diseases or hospital records. Doctors in private practice claimed that they could attract patients by maintaining greater confidentiality.

Managing intravenous drug users - Fifty general practitioners asked all new patients joining their practices about their use of drugs, while most of the remainder asked only when suspicious. Few doctors (11) never sought this information from their patients. Over one quarter (72), however, would not accept known intravenous drug users either as temporary or as permanent patients, while a further 20 would accept them only if they were permanent patients and 11 only if temporary. In addit: $n$, doctors were generally reluctant to undertake management of drug dependence. Two hundred and sixteen referred all intravenous drug users to drug dependency units for supervision of their specific 
drug problem. Sixty seven, however, prescribed maintenance treatment with methadone at least occasionally, and 43 handled all their patients' drug, physical, and psychological problems. Although 152 doctors believed that needles and syringes should be available on the premises to reduce the spread of HIV infection among drug users, only 18 claimed that they currently supplied them and only four did so regularly.

Managing homosexual patients-A substantial minority of practitioners (39) regarded sexual orientation as a private matter and therefore never asked patients for this information. Although 32 claimed that they asked all new patients about their sexual orientation at registration, the remainder usually asked only when patients presented with worries about HIV infection or marital or sexual problems. Just under a half (120) did not believe that homosexual people had any particular needs over and above those of other patients. Among the majority who did consider that they had specific needs principal concerns included counselling and education about AIDS, sexually transmitted diseases, and sexual problems and help with problems of lifestyle. Current legal constraints on homosexual behaviour were considered satisfactory by 181 general practitioners, while 67 favoured more liberal and 15 less liberal legislation.

Ethical considerations - Doctors were asked how they would treat a man positive for HIV antibody with a regular sexual partner who was unaware of the man's HIV state. They were then asked to reconsider their answer with two added provisos, the first being that the sexual partner was the man's wife and the second that the sexual partner was also a patient of the doctor. In all three circumstances over four fifths claimed that they would try to persuade the patient to inform his partner while respecting confidentiality by ultimately leaving the decision to him.

\section{OPINIONS AND PRACTICE OF DOCTORS WITHOUT} PATIENTS WITH HIV INFECTION

The 97 doctors without patients with HIV infection were older (mean difference 5.8 years, $95 \%$ confidence interval 2.7 to $8.9 ; t=3.75 ; \mathrm{df}=261 ; \mathrm{p}<0.001)$; had been in general practice longer $(4.6$ years, 1.5 to $7 \cdot 7$; $t=3.08 ; \mathrm{df}=265 ; \mathrm{p}<0.003)$; and were more likely to work single handedly $\left(15.5 \% ; 4.8\right.$ to $26 \cdot 2 ; \chi^{2}=9 \cdot 3$; $\mathrm{df}=1 ; \mathrm{p}<0.003)$. These doctors were less likely to report consultations with patients obsessively concerned about contracting HIV infection $(27 \%, 14.4$ to $\left.39.6 ; \chi^{2}=14.6 ; \mathrm{df}=1 ; \mathrm{p}<0.001\right)$; to be prepared to register known intravenous drug abusers as permanent $\left(19 \%, 7.4\right.$ to $\left.30.6 ; \chi^{2}=11.2 ; \mathrm{df}=1 ; \mathrm{p}<0.002\right)$ or temporary patients $\left(14 \%, 2 \cdot 2\right.$ to $25 \cdot 8 ; \chi^{2}=5 \cdot 7 ; \mathrm{df}=1$; $\mathrm{p}<0.02)$; to counsel heterosexuals $(12.5 \%, 2.6$ to 22.4 ; $\left.\chi^{2}=6.3 ; \mathrm{df}=1 ; \mathrm{p}<0.02\right)$ or homosexuals $(31.4 \%, 18 \cdot 8$ to $\left.44 ; \chi^{2}=22 \cdot 8 ; \mathrm{df}=1 ; \mathrm{p}<0.001\right)$ about safer sexual practices; and to consider that condoms should be freely available in their surgery $(13.2 \%, 1.8$ to $24 \cdot 6$; $\left.\chi^{2}=5.24 ; \mathrm{df}=1 ; \mathrm{p}<0.03\right)$. They were also more likely to be in favour of the policies of insurance companies $\left(13 \%, 0.2\right.$ to $\left.25 \cdot 8 ; \chi^{2}=4 \cdot 2 ; \mathrm{df}=1 ; \mathrm{p}<0.05\right)$. Although doctors with patients with HIV were more likely to have attended a study day on AIDS, this was not significant.

\section{Discussion}

A substantial proportion of general practitioners in London are closely involved in the care of patients with HIV and are making use of opportunities for postgraduate education on AIDS. Two thirds of the doctors interviewed had treated at least one patient with HIV infection. Over half had been approached by a person concerned about AIDS in the month before interview, and most had considered a test for HIV in at least one patient. A further half had patients who were constantly consulting them, being fearful of having contracted AIDS. Finally, four fifths were educating their heterosexual patients about sexual practices and the risks of HIV infection. Doctors engaged in primary care in Britain seem to be strongly committed to providing continuing care for this group of patients.

Although a small number of patients had told their doctors that they had been refused treatment by previous general practitioners, it is important to consider in what context this took place. Difficulty in registering with a family doctor can occur for several reasons, including the list size of the doctor, and may be misinterpreted by patients sensitive about their diagnosis. When patients are asked directly about their relationship with their doctor, reports of rejection are extremely rare. ${ }^{+}$

Most general practitioners seemed to be confidently counselling patients before a test for HIV antibody, which is more reassuring than recent reports of up to $60 \%$ of primary care doctors in south London being uncertain about providing counselling on AIDS. ${ }^{1016} \mathrm{It}$ also shows that most family doctors already regard counselling as an integral part of their work despite calls for specific training for the task. ${ }^{17}$ Perhaps surprisingly, far fewer doctors counselled patients after the test. There remains a need for education and support of people after a test for HIV regardless of the outcome. The doctors were well informed on support and educational facilities, particularly charities such as the Terrence Higgins Trust, and seemed to use these more specifically for support after the diagnosis was known.

Although in accord with clinical studies ${ }^{18-20}$ in reporting anxiety and depression as the commonest psychological problems in their patients with HIV infection, these doctors rarely encountered cognitive difficulties. Cognitive changes may be subtle and not readily recognised until patients are in the more advanced, rapidly progressive stages of disease, ${ }^{1921}$ when they are perhaps less likely to be treated in primary medical care.

Most family doctors regarded the patient's home as the most suitable place for terminal care and, with the help of ancillary workers, were starting to take part in this work. General practitioners were also in contact with the sexual partners, families, and friends of their patients with HIV infection, whose principal concerns were a fear of contamination rather than a need for advice on the care of their affected relative or friend. The family doctor is well placed to provide health education for these groups.

The doctors were polarised on the issue of insurance. Although almost half were in favour of the policies of companies, many of the remainder refused to cooperate. Interestingly, almost two thirds of doctors interviewed claimed that they showed patients their medical reports before they were given to the insurance company. This contrasts with the results of a recent survey of patients in England whose general practitioners had recently issued medical reports for insurance purposes. ${ }^{22}$ Just over half of patients could not recall having given informed consent, and over half expected their doctor to withhold sensitive information. Perhaps general practitioners in London, with their greater exposure to issues on HIV infection, are more aware of the difficulties of insurance reports.

Soon after the completion of the interviews reported here the Royal College of General Practitioners recommended removing the onus on the family doctor to answer questions from insurance companies on possible HIV infection in their patients (second council meeting, December 1988). This should go some way to easing patients' fears about confidentiality ${ }^{2324}$ and their dislike of these questions. ${ }^{22}$ The approach in Sweden,,$^{25}$ 
where a government all party committee has actively discouraged insurance companies from identifying patients with HIV infection could be emulated in the United Kingdom, albeit at an increased cost to those with insurance.

Few doctors were testing patients for HIV antibody without their consent, which confirms other work with both patients and doctors ${ }^{12}$ and is in line with medicolegal ${ }^{26}$ and ethical ${ }^{27}$ opinion. Earlier claims that most doctors in primary care were prepared to test without consent under special circumstances and that between a third and half would favour compulsory screening of groups at risk, ${ }^{9}$ were not upheld.

Unfortunately, a considerable number of general practitioners flag the notes of their patients with HIV infection and are satisfied with the confidentiality of these records, both of which are the object of considerable suspicion for patients. ${ }^{+5}$ Most staff will be aware of patients with HIV infection known to their practice, and there seems little advantage in adding a tag that patients find stigmatising. Beyond a certain complacency on the security of their practice records, confidentiality is clearly important to these doctors as most would not alert the unsuspecting sexual partner of a patient with HIV infection even if that partner was also on their list and despite implicit permission to do so by the General Medical Council ${ }^{28}$ and current ethical opinion. ${ }^{27}$

Although accepting homosexual patients, these general practitioners were less willing to take on drug abusers, confirming similar findings from other surveys. ${ }^{12}{ }^{29}$ Paradoxically, most claimed that they were prepared to take part in needle exchange schemes from their practices; few, however, had actually put such schemes into action. It is worrying that over one quarter of these doctors would not accept known drug abusers as patients and a further $30(11 \%)$ would accept them only under defined conditions. This was reflected in the large numbers of drug abusers who had complained to their doctor that they had been removed from the lists of previous general practitioners. Although drug addiction presents general practitioners with a large workload and many of the more difficult cases must be catered for in special units, the general practitioner remains a key figure. ${ }^{30}$ The care of drug abusers in primary medicine requires urgent review.

Doctors without patients with HIV infection in their care reported fewer consultations with people fearful about HIV infection and took less interest in counselling and educating their patients about AIDS and associated risk behaviours. Although there was a trend for these doctors to have attended postgraduate teaching on AIDS less often than their colleagues with patients with HIV infection, it would seem that at least some experience with patients with HIV infection is more important in sensitising doctors to these issues.

Regular surveillance of patients positive for HIV antibody can be provided as well in general practice as in specialist clinics. ${ }^{1+31}$ Primary care doctors in London have become a part of the community team caring for patients with HIV infection and AIDS: Their preparedness to be involved seems to exceed that of general dental practitioners in the United Kingdom, who refer away more than half of patients known to be infected with HIV. ${ }^{32}$ Difficulties remain in defining their role as they do not come within the remit of health authorities in the same way as do other doctors and health professionals. ${ }^{33}$ There continues to be no evidence that patients are rejected or in any way given inferior treatment ${ }^{+}$as has sometimes been claimed in the United Kingdom ${ }^{3+35}$ and other countries. ${ }^{3637}$

I thank Drs A Charters, A Gillham, H Guite, J Kirton, C Makin, P Mallett, S McCullough, L Mehta, I Nazareth, M Orgel, M Robinson, V Rowe, J Sanders, and J Shaw, who acted as interviewers; Mrs Brenda Robinson for her administrative help; and all the general practitioners who gave their time to take part in the study. The project was supported by the Department of Health, Mental Health Foundation, and Association of British Insurers.

1 Ward M, Papadakis MA. Untrapping the metaphor of AIDS. Am $\mathcal{f}$ Med 1987;83:1135-7.

2 Bucknall A. Regional pattern of AIDS and HIV infection. $f R$ Coll Gen Pract 1986;36:491-2

3 Working Party of the Royal College of General Practitioners. Human immunodeficiency virus infection and the acquired immune deficiency syndrome in general practice. $\mathcal{F} R$ Coll Gen Pract 1988;38:219-25.

$4 \mathrm{King}$ MB. AIDS and the general practitioner: views of patients with HIV infection and AIDS. $\mathrm{Br}$ Med $\mathrm{f}$ 1988;297:182-4.

5 Mansfield SJ, Singh S. The general practitioner and human immunodeficiency virus infection: an insight into patients' attitudes. $\exists R$ Coll Gen Pract virus infection:

6 Searle ES. Knowledge, attitudes, and behaviour of health professionals in relation to AIDS. Lancet 1987;i:26-8.

7 Anderson P, Mayon-White R. General practitioners and management of infection with HIV. Br.Med f 1988;296:535-7.

8 Milne RIG, Keen SM. Are general practitioners ready to prevent the spread of HIV? Br Med f 1988;296:533-5.

9 Boyton R, Scambler G. Survey of general practitioners' attitudes to AIDS in the North West Thames and East Anglian regions. Br Med $\mathcal{f}$ 1988;296: 538-40.

10 Sibbald B, Freeling P. AIDS and the future general practitioner. $f$ R Coll Gen Pract 1988;38:500-2

11 Shapiro J. General practitioners' attitudes towards AIDS and their perceived information needs. Br Med F 1989;298:1563-6.

12 King MB. London general practitioners' involvement with HIV infection. fR Coll Gen Pract 1989;39:280-3.

13 Naji SA, Russell IT, Foy CJW, Gallagher M, Rhodes T, Moore MP. HIV infection and Scottish general practice: knowledge and attitudes. $\mathcal{F} R$ Coll Gen Pract 1989;39:284-8.

14 Adler MW. Care for patients with HIV infection and AIDS. Br Med $\mathcal{J}$ 1987;295:27-30.

15 Anonymous. AIDS, HIV and general practice [Editorial]. $f R$ Coll Gen Pract 1987:37:289-91.

16 Sibbald B, Pharoah C, Freeling P, Anderson HR. AIDS-is general practice meeting the challenge? I $R$ Coll Gen Pract 1988;38:32.

17 Rowland N, Irving J, Maynard A. Can general practitioners counsel? $\mathcal{F} R$ Coll Gen Pract 1989;39:118-20.

18 Dilley JW, Ochitill HN, Perl M, Volberding PA. Findings in psychiatric consultations with patients with acquired immune deficiency syndrome. Am F Psychiatry 1985;142:82-6.

19 Catalan J. Psychosocial and neuropsychiatric aspects of HIV infection: review of their extent and implications for psychiatry. $\mathcal{F}$ Psychosom Res 1988;32: $237-48$

20 King MB. Psychosocial status of 192 outpatients with HIV infection and AIDS. Br f Psychiatry 1989;154:237-42.

21 Colon EA. Neuropsychiatric aspects of infection with the human immunodeficiency virus. Current Opinions in Psychiatry 1988;1:5-12.

22 Lorge RE. How informed is patients' consent to release medical information to insurance companies? Br.Med f 1989;298:1495-6.

23 Gallagher $M$. AIDS and HIV infection: ethical problems for general practitioners. I R Coll Gen Pract 1988;38:414-7.

$24 \mathrm{King}$ MB. HIV infection: ethical problems for general practitioners. $\mathcal{F} R$ Coll Gen Pract 1988;38:521-2.

25 Bird AG. HIV infection: the Swedish approach: a Medicine-Gilliland Fellowship report. I R Coll Physicians Lond 1988:22:114-7.

26 Sherrard M, Gatt I. Human immunodeficiency virus (HIV) antibody testing. BrMed f 1987;295:911-2.

27 Black D. Ethics of HIV testing: a personal view. $\mathcal{I} R$ Coll Physicians Lond 1989;23:19-21.

28 General Medical Council. HIV infection and AIDS: the ethical considerations. London: General Medical Council, 1988.

29 Glanz A. Findings of a national survev of the role of general practitioners in the treatment of opiate misuse: views on treatment. Br Med F 1986;293:543-55. treatment of opiate misuse: views on treatment. Br Med f 198

30 Richards T. Drug addicts and the GP. Br.Med $1988 ; 296: 1082$. practitioner. FAMA 1989;261:555.

32 Matthews RW, Dowell TB. Attitudes and practices regarding control of cross Matthews RW, Dowell TB. Attitudes and practices regarding con
infection in general dental practice. Health Trends 1989;21:11-3.

33 Crown J. Planning services within the NHS. In: Clarkson P, ed. Planning local services. Report of a conference for local authorities, health authorities and voluntury organisations in London. London: King's Fund Centre, 1987:17-23. (Project paper 68.)

34 Hill B. Patients advised to conceal AIDS from doctors. Doctor 1986;16:17.

35 House of Commons Social Services Committee. Problems associated with AIDS. Third report from the social services committee session 1986-87. London: House of Commons, 1987.

36 Lewis CE, Freeman HE, Corey CR. AIDS-Related competence of California's primary care physicians. Am f Public Health 1987;7:795-9.

37 Kelly JA, Lawrence JS, Smith S, Hood HV, Cook DJ. Stigmatization of AIDS patients by physicians. Am J Public Health 1987;7:789-91.

(Accepted 26 fuly 1989) 